\title{
GRID-SCALE EXPLORATION OF THE RELATIONSHIP BETWEEN ECOLOGICAL HEALTH AND HUMAN PRESSURE IN THE THREE GORGES RESERVOIR REGION
}

\author{
XIAO, Z. L. ${ }^{1,2,3}-$ GAO, Y. H. ${ }^{1 *}-$ YANG, Q. Y. ${ }^{3}$ \\ ${ }^{1}$ Chongqing institute of meteorological sciences, Chongqing 401147, China \\ ${ }^{2}$ Chongqing Key Laboratory of GIS Application Research, Chongqing Normal University, \\ Chongqing 401331, China \\ ${ }^{3}$ School of Geographical Sciences, Southwest University, Chongqing 400715, China \\ ${ }^{*}$ Corresponding author \\ e-mail: gaoyanghua@sina.com \\ (Received $8^{\text {th }}$ Sep 2021; accepted $23^{\text {rd }}$ Nov 2021)
}

\begin{abstract}
Human activity is becoming the key factor influencing ecological health changes and clarifying the nature of that influence could effectively promote regional ecological restoration. Commonly used human-related factors (e.g., social and economic census data) can only be constrained at the administrative division, and they lead to a loss of detailed spatial characteristics. In this study, we applied human activity intensity (HAI), mapped at the grid scale, to represent pressures of human activity on the ecosystem. Taking the Three Gorges Reservoir Region (TGRR) as the study area, the spatial heterogeneity of the influences of human pressure on ecological health was analyzed. The results showed that, in the TGRR from 2000 to 2018, there was an overall improvement of ecological health and a significant spatial reorganization of HAI. The impact of HAI on ecological health had significant spatial heterogeneity. In areas where HAI had decreased, ecological health was prone to improve significantly. In contrast, in areas where HAI had increased, ecological health tended to become worse, and only when the increase of HAI exceeded 0.08 would that tendency be significant. Compared to urban areas, HAI change had even broader impacts on ecological health in remote mountain areas, where a more remarkable restoration of the ecosystem was experienced.
\end{abstract}

Keywords: ecosystem health, human activity intensity, spatial heterogeneity, finer scale, GIS

\section{Introduction}

Ecological health and its evaluation have played a critical role in human sustainable development (Sivakumar, 2007; D'Odorico et al., 2013). Studies show that human activity and natural factors could both strongly affect ecological health evolution (Shi et al., 2007; Sun et al., 2012; Ma et al., 2013, 2014). With the human population increasing to 9.1 billion by 2050, followed by accelerating urbanization and increasing challenges of generating enough food, human pressure on ecological health is becoming increasingly important and could generate a decisive influence on ecological health in a shorter amount of time (Halpern et al., 2008; Cao et al., 2014; Feng et al., 2015). This situation is highlighted in the Three Gorges Reservoir Region (TGRR) (Chen et al., 2019).

The world-famous Three Gorges Dam, as the largest hydroelectric project along the Yangtze River (Nilsson et al., 2005), has formed a unique geomorphological region called the Three Gorges Reservoir Region (Shao et al., 2018) that covers a total water and land surface area of $57,900 \mathrm{~km}^{2}$, comprising 20 county-level divisions of the Chongqing municipality and Hubei province in China. Because of its special geographic 
environment, TGRR is characterized by typical ecological fragility with serious conflicts between the increasing human population and limited land surface. The construction of the hydroelectric project itself and the following strenuous adjustment in TGRR, such as resettlements of environmental migrants and the removal and reconstruction of towns, made the TGRR experience a remarkable spatial reorganization of the human factor in recent decades, suffering from a series of unprecedented ecological problems. Studying the relationship of human pressure and ecological health in TGRR is helpful for local ecological restoration, providing an important reference for the planning of large hydroelectric project constructions in other areas.

Costanza et al. (1992) first defined the concept of ecosystem health, which refers to the ability to keep its structure and recover by itself after disturbances. Myneni et al. (1992) reported that "ecological health is closely linked to the idea of sustainability, which is seen to be a comprehensive, multiscale, dynamic measure of system resilience, organization, and vigor". In recent decades, ecological health evaluation has become a research hotspot, and has been carried out in different areas and ecosystem types (Wu et al., 2018). The pressure-state-response (PSR) framework has been widely adopted to evaluate ecological health, which classifies ecological indicators on the basis of interactions between humans and ecosystems (Neri et al., 2016; Schumacher et al., 2016). The PSR framework performs well on ecological health simulation on the grid scale for studying spatial heterogeneity evolution (Allen et al., 2002), which is critical for detecting detailed spatial characteristics of ecological health evolution. However, with regard to the relationship between ecological health and human activity, the consideration of spatial heterogeneity in existing studies is insufficient ( $\mathrm{Li}$ and $\mathrm{Li}, 2014$; Jin et al., 2016; Niu et al., 2017). The main reason is that commonly used human-related factors (e.g., social and economic census data) can only be constrained at the administrative division in terms of scale. Therefore, when dealing with the impacts of human pressure on ecological health evolution, previous studies often focused on their statistical relationships by treating administrative divisions as sampling units (Zhao et al., 2016; He et al., 2019); others were usually conducted based on a limited number of the on-site samples which are incomplete and unsystematic (Zhang et al., 2013; Bebianno et al., 2015; Tang et al., 2015; Li et al., 2017). Thus, an in-depth study at finer scale is urgently needed. Particularly for the TGRR, this specific region having a highly discretized ecosystem in complex terrain and experiencing remarkable spatial reorganization due to human factors, the spatial heterogeneity of the relationship between ecological health and human pressure should be studied for the better understanding of the mechanism of human activity on ecological health evolution, and to provide better references for maintaining and recovering ecological health.

Because of the shortcomings of commonly used human-related factors, we applied human activity intensity (HAI) to quantitatively represent human influence on the ecosystem. HAI was proposed by Sanderson et al. (2002), and could be mapped at the grid scale by using four human pressure types (i.e., land use, population density, road distribution, and grazing density) on land on the basis of integrated GIS techniques (Li et al., 2018). Its comprehensiveness and availability on a fine scale made the HAI index an ideal proxy of human pressure on the ecosystem for our study. Therefore, the objective of this study was to calculate the ecological health of the study area by using PSR and map the HAI at the grid scale, then quantitatively analyzed the temporal-spatial change characteristics of ecological health and HAI, and their relationship. 


\section{Materials and Methods}

\section{Study Area}

The Three Gorges Reservoir Region is a modern geographical concept that refers to the region directly or indirectly influenced by the construction of the Three Gorges Dam, comprising 20 county-level divisions of Chongqing and Hubei province of China, with a total area of $57,900 \mathrm{~km}^{2}$. Our study selected the section located in Chongqing province, accounting for $85 \%$ of the whole TGRR, as the study area (Fig. 1), which stretches along the Yangtze River from Jiangjin to Wushan county in Chongqing. The 20 counties of the study area can be classified into two categories. There are 9 developed counties including Nanan, Jiangbei, Yubei, Yuzhong, Beibei, Shapingba, Jiulongpo, Dadukou and Banan, which cluster together and form a metropolitan region of Chongqing province. The other counties all belong to developing counties, mainly distributed in remote mountainous areas. The study area consists mainly of mountainous and hilly areas representing $74 \%$ and $21.7 \%$ of the region, respectively, with only $4.3 \%$ of the plain areas in the river valley. This region belongs to the transition zone between the northern temperate and subtropical zones, and has typical subtropical monsoon climate characteristics with high temperatures (annual mean temperature is $18.2^{\circ} \mathrm{C}$ ) and large amounts of precipitation (annual mean precipitation is $1200 \mathrm{~mm}$ ) (Wang and Geng, 2013). The study area has various land-use types, with forestland accounting for the largest proportion (48.9\%) of the total area. Agricultural land is the second major land-use type, with a proportion of $14.4 \%$. In 2016, the study area had a total year-end population of 14.8 million, and GDP of RMB 776.6 billion (Ding et al., 2020). In recent years, the importance of the economic and ecological status of TGRR has been gradually recognized, and a favorable situation of its ecological health is becoming the basic guarantee for the sustainable development of the Yangtze economic zone.

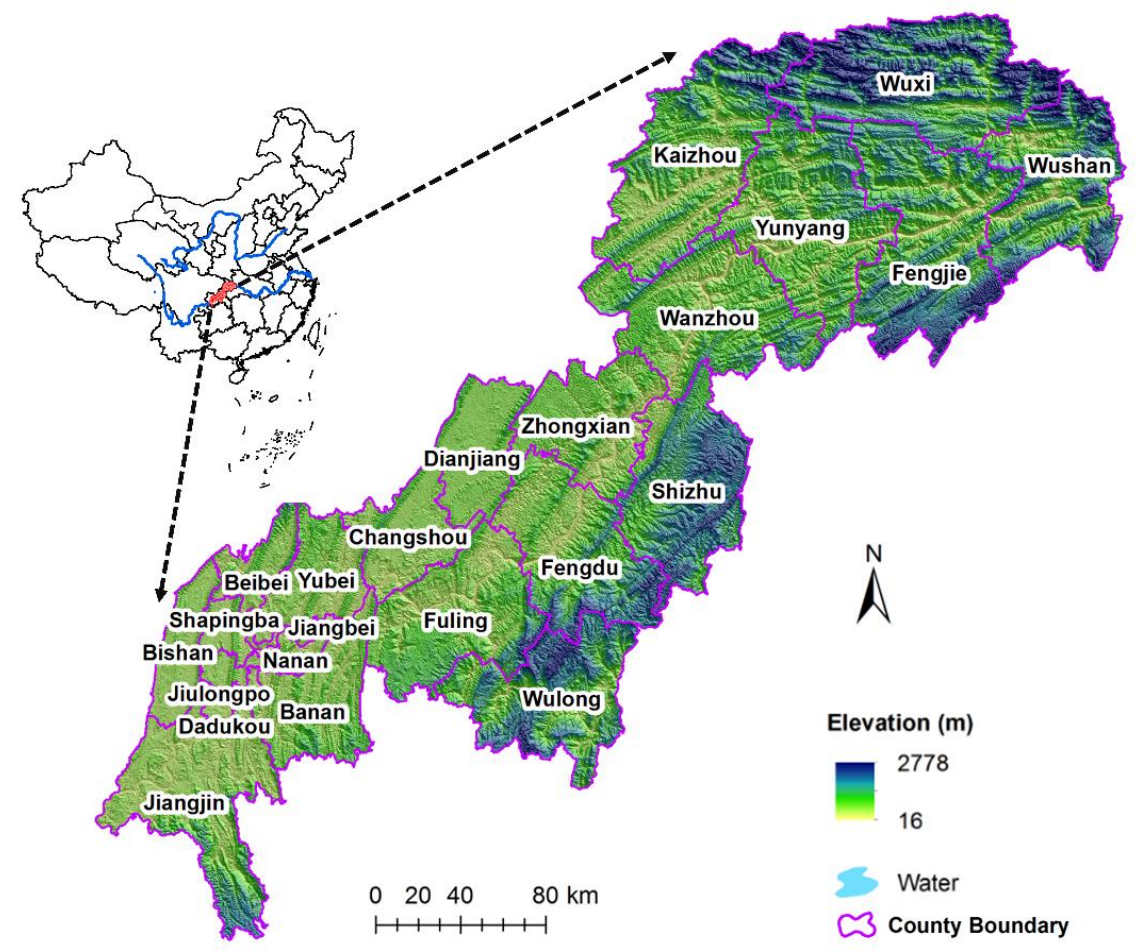

Figure 1. Study area 


\section{Data Sources}

By using the visual interpretation method, we applied the Landsat Thematic Mapper (TM) and Operational Land Imager (OLI) to produce the land-use dataset for 2000 and 2018, respectively (Table 1). All TM/OLI images, and the atmospheric correction before the interpretation, were georeferenced. We used survey results, conducted in 2018 by our study group, to validate the land-use dataset, and found that the overall accuracy of the land-use dataset in 2018 was $93 \%$. We classified land-use types into six groups: farmland, forestland, grassland, water areas, wetland, and urban and rural settlements. Spatialized population data with a spatial resolution of $500 \mathrm{~m} \times 500 \mathrm{~m}$ for 2000 and 2018 were provide by the Data Center for Resources and Environmental Sciences, Chinese Academy of Sciences (http://www.resdc.cn). We adopted a MODIS vegetation index (VI) product with spatial resolution of $500 \times 500 \mathrm{~m}$ and temporal resolution of 16 days obtained from NASA's Earth Observing System to produce the normalized difference vegetation index (NDVI) dataset. First, the maximum value composite (MVC) method was applied to generate the monthly NDVI for 2000 and 2018, respectively. Then, the values of the monthly NDVI from April to November were averaged to obtain the growing-season NDVI (GSN). The GSN is a robust approximation of the vigor of the ecosystem (Tong et al., 2016). Road distribution data for 2000 and 2018 were extracted from the traffic map of Chongqing province, published by the Chongqing Surveying and Mapping Bureau. Grazing density data were extracted on the basis of the land-use dataset according to research of Li et al. (2018).

Table 1. Description of data

\begin{tabular}{|c|c|c|c|}
\hline Name & Type & Scale/Resolution & Sources \\
\hline TM/OLI images & grid & $30 \mathrm{~m} \times 30 \mathrm{~m}$ & $\begin{array}{c}\text { The Institute of Remote Sensing and } \\
\text { Digital Earth, Chinese Academy of } \\
\text { Sciences (CAS) }\end{array}$ \\
\hline Spatialized population data & grid & $500 \mathrm{~m} \times 500 \mathrm{~m}$ & $\begin{array}{c}\text { The Data Center for Resources and } \\
\text { Environmental Sciences, CAS }\end{array}$ \\
\hline $\begin{array}{l}\text { MODIS vegetation index (VI) } \\
\text { product }\end{array}$ & grid & $500 \mathrm{~m} \times 500 \mathrm{~m}$ & NASA's Earth Observing System \\
\hline Road distribution data & $\operatorname{shp}$ & $1: 100,000$ & $\begin{array}{c}\text { Chongqing Surveying and Mapping } \\
\text { Bureau }\end{array}$ \\
\hline Grazing density data & grid & $30 \mathrm{~m} \times 30 \mathrm{~m}$ & Extracted based on land-use dataset \\
\hline
\end{tabular}

\section{Methodology}

\section{Ecological Health Evaluation}

The PSR model, which was initially proposed by the Organization of Economic CoOperation and Development (OECD), was applied to evaluate the ecological health of the study area (Walz, 2000). The framework comprises three parts, pressure (P), state (S) and response (R). Each part can be complex when developed into different levels. According to the PSR model associated with our study aims, and data availability on the regional scale, we established a three-level index system for ecological health assessment in the TGRR (Table 2). Seven indices, weighted by the analytic hierarchy process (AHP) (Saaty and Vargas, 2001), were applied as the proxy of the pressure, state, and response of the study area ecosystem. Each index was standardized into an interval of (0-1) for comparison analysis. A larger value meant a better ecosystem 
condition. The combination of all standardized indices refers to ecological health (EH), which was calculated by using Equation (1):

$$
E H=\sum_{i=1}^{n} W_{i} * A_{i}
$$

where, $n$ is number of indices; ${ }^{W}$, weight of index $i$; and ${ }^{A_{i}}$, value of index $i$, which is standardized. The larger EH is, the better the ecological health, and vice versa.

Table 2. Index system for ecological health assessment

\begin{tabular}{c|c|c|c}
\hline Target Level & \multicolumn{2}{|c|}{ Standard Level } & Index Level \\
\hline \multirow{3}{*}{$\begin{array}{c}\text { Ecological health } \\
\text { assessment }\end{array}$} & \multicolumn{2}{|c}{ Pressure $(0.3)$} & Population Density \\
\cline { 2 - 3 } & \multirow{3}{*}{ State $(0.6)$} & Vigor $(0.13)$ & NDVI \\
& & Organization $(0.2)$ & Landscape diversity $(0.1)$ \\
& & Function $(0.2)$ & Average patch area (0.1) \\
& \multicolumn{2}{|c}{ Resilience $(0.07)$} & Ecological service value \\
\cline { 2 - 3 } & \multicolumn{2}{|c}{ Response $(0.1)$} & Ecological resilience \\
\hline
\end{tabular}

The produce of each index is as follows:

Population density: spatial population density data were applied to represent human pressure intensity.

NDVI: It could effectively measure the vigor of the vegetation cover. In our study, the NDVI was obtained from the MODIS vegetation index product by using the maximum value composite (MVC) method, which minimizes effects from cloud contamination.

Landscape diversity and average patch area: The organization index represents the complexity of ecosystem structure, which was characterized by using two landscape ecology indices (landscape diversity and average patch area) in this study. The two landscape ecology indices were produced by using the Fragstats software (Wu, 2000).

Ecological service value: Ecosystem services are benefits that human directly or indirectly gain from an ecosystem, such as water conservation, waste disposal and food production. In this study, the ecological service value was extracted from land use data according to the research of Xie et al. (2003), and Liao et al. (2018) (Table 3).

Ecological resilience: Ecological resilience represents the capacity of the ecosystem to withstand disturbances from natural and human activities (e.g., climate change and deforestation). Ecological resilience could be valued by using the ecological resilience index (ERI), which was calculated by using Equation (2):

$$
E R I=L D \times \sum_{i=1}^{n} R_{i} * S_{i}
$$

where $L D$, landscape diversity index; ${ }^{R}$, area ratio of landscape type $i$ to the study area; and $S_{i}$, resilience value of landscape type $i$, which is referred to in the study of Du et al. (2013). 
Table 3. Ecosystem service value $\left(¥ / \mathrm{hm}^{2}\right)$ for different land use types derived from Xie et al. (2003), and Liao et al. (2018)

\begin{tabular}{c|c|c|c|c|c|c}
\hline & Forest & Grass & Water & Farmland & Urban & Other \\
\hline Gas regulation & 3097 & 707.9 & 1592.7 & 442.4 & 0 & 0 \\
Climate regulation & 2389.1 & 796.4 & 15130.9 & 787.5 & 407 & 0 \\
Water conservation & 2831.5 & 707.9 & 13715.2 & 530.9 & 18033.2 & 26.5 \\
Soil formation & 3450.9 & 1725.5 & 1513.1 & 1291.9 & 8.8 & 17.7 \\
Waste disposal & 1159.2 & 1159.2 & 16086.6 & 1451.2 & 16086.6 & 8.8 \\
Bio-diversity & 2884.6 & 964.5 & 2212.2 & 628.2 & 2203.3 & 300.8 \\
Food production & 88.5 & 265.5 & 265.5 & 884.9 & 88.5 & 8.8 \\
Raw materials & 2300.6 & 44.2 & 61.9 & 88.5 & 8.8 & 0 \\
Entertainment & 1132.6 & 35.4 & 4910.9 & 8.8 & 3840.2 & 8.8 \\
Total & 19334 & 6406.5 & 55489 & 6114.3 & 40676.4 & 371.4 \\
\hline
\end{tabular}

Landscape fragmentation: It reflects composite information containing both the complexity of the landscape pattern and the intensity of human activity. According to the research of Chen (2007), we adopted landscape fragmentation as the proxy of the response from human activity. The landscape fragmentation index was calculated on the basis of land use data by using Equation (3):

$$
L_{i}=N_{i} / S_{i}
$$

where $L_{i}$, landscape fragmentation index of landscape $i ; N_{i}$, number of patches of landscape $i$; and $S_{i}$, area of landscape $i$.

\section{Mapping of Human Activity Intensity (HAI)}

In the Anthropocene era, humans have dramatically influenced the ecosystem. Mapping human activity intensity (HAI), that is, quantitatively expressing the human pressure on a grid scale, is an important way to promote the study between the humans and ecosystems (Li et al., 2018). In this paper, we mapped TGRR HAI on a $500 \times 500 \mathrm{~m}$ grid in 2000 and 2018 by tailoring the methodology of Sanderson et al. (2002). By considering the regional, biophysical, and cultural characteristics of the TGRR, we selected land use, population density, road accessibility, and grazing density as geographic input datasets. Then, each input dataset was normalized and assigned relative pressure scores of human activity intensity. Lastly, we summed up the humanactivity scores for each of the four datasets to calculate human activity intensity.

\section{Results and Discussion}

\section{Variation Characteristics in Ecological Health and HAI between 2000 and 2018}

According to our estimates, the averaged grid-value of the ecological health map in 2000 was 0.54, and the corresponding value in 2018 was 0.61 , which indicated an overall improvement of ecological health in the Three Gorges Reservoir Region from 2000 to 2018. With regard to the standardized indices referring to ecological health 
(Fig. 2), we yielded the averaged grid-value as follows: resilience index (0.40), vegetation vigor (0.60), organization index (0.30), ecosystem service index (0.12), fragmentation index (0.63), and population density index (0.99). The corresponding values in 2018 were $0.47,0.77,0.40,0.16,0.67$, and 0.98 , respectively. From 2000 to 2018 , except for the population density index, which slightly decreased, the other five standardized indices all increased to some extent. The decrease in the population density index, where a larger value means a better ecosystem condition, could be explained by the increase in population in recent decades in the study area (Shao et al., 2018).
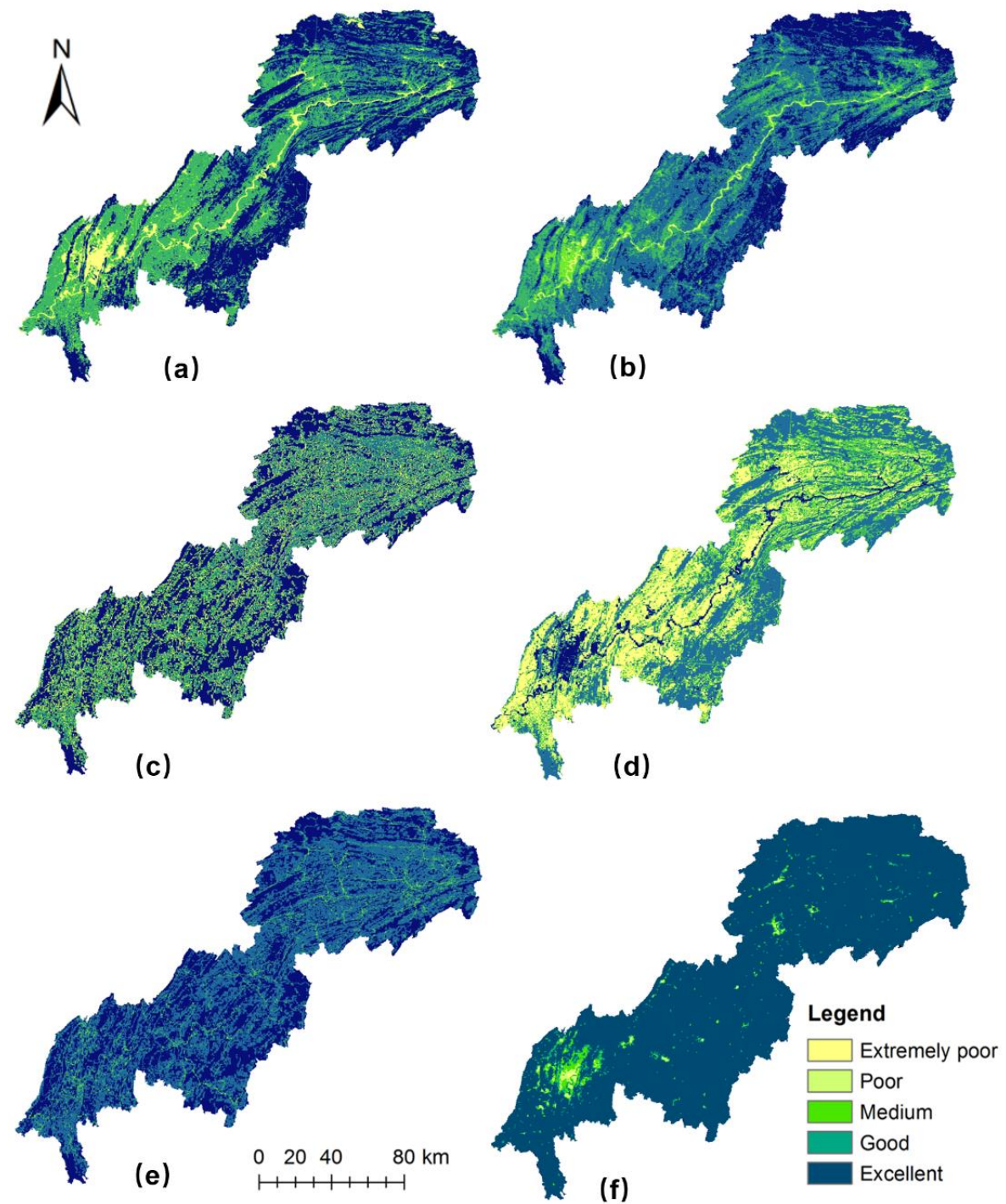

Figure 2. Different standardized indices describing ecological health for 2018. (a) Ecological resilience index; (b) NDVI as proxy for vegetation vigor; (c) organization index; (d) ecosystem services index; (e) fragmentation index; $(\boldsymbol{f})$ the population density index

By using GIS technology, we generated ecological health and HAI changes from 2000 to 2018, respectively (Fig. 3), which provided detailed spatial information for better understanding the relationship between ecological health evolution and human activity disturbances. Figure $3 a$ shows that, despite an overall improvement, there were 
some areas that experienced deterioration, which accounted for $13.3 \%$ of the total study area according to our statistics. The most obvious deterioration occurred in a region in the shape of a circle, located in the southwestern part of the study area (Fig. 3a). This region is the metropolitan area of Chongqing province, with high human activity density (Fig. 3b), and it has been experiencing a rapid urban expansion process while occupying farmlands (Liu et al., 2018). Therefore, urban expansion might trigger the formation of the deterioration circle of the ecological system.

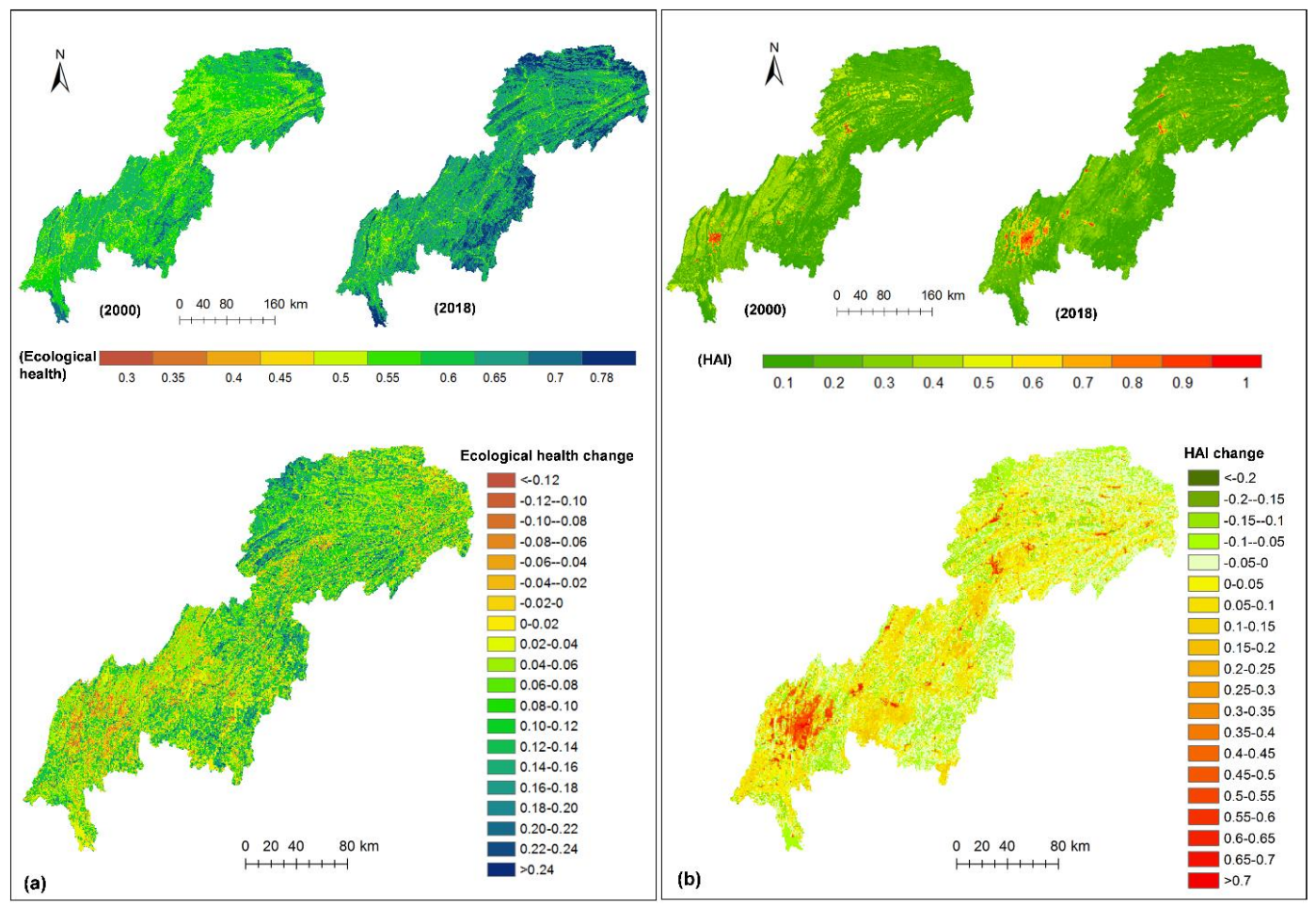

Figure 3. (a) Ecological health of 2000 and 2018, and ecological health changes from 2000 to 2018; (b) human activity intensity (HAI) of 2000 and 2018, and HAI changes from 2000 to 2018

According to Figure $3 b$, we could confirm the significant spatial reorganization of human activity intensity from 2000 to 2018 in the study area. About $77.93 \%$ of the total study area experienced an increase in HAI. The most obvious increase occurred in the metropolitan areas, and grids experiencing a decrease in HAI were distributed mainly in remote mountainous areas with high elevation and steep slopes (Figs. 1 and 3b). This phenomenon could be closely related to population movements, peasants migrating from villages to cities, which happened in the wide mountainous regions in China (Zhang et al., 2018). In mountainous areas, the outmigrant population directly relieved pressure from human activity on local ecosystems. Conversely, in the city area, ecosystems might suffer more from human disturbance because of immigrant populations. To sum up, in the Three Gorges Reservoir Region, from 2000 to 2018, the temporal and spatial changes of ecological health and human activity intensity were both significant. From the perspective of spatial detail mining, the relationship between ecological health and human pressure could be very complicated. 


\section{Relationships between Human Activity Intensity and the Ecological Health Evolution}

In order to quantitatively clarify the relationship between HAI and ecological health, linear regression analysis was used to treat samples extracted from two different scales, respectively. There are 24 counties (administrative region unit) in the study area (Fig. $4 f$ ). We averaged the grid values for each county in terms of ecological health and HAI and their changes for 2000 and 2018, and then plotted them on a scattered point diagram (Fig. 4a-c). We also generated 1930 uniformly distributed sample points in the study area (Fig. $4 f$ ) in the GIS environment to mine on a finer scale the influence characteristics of HAI changes on ecological health changes. The 1930 sample points were classified into two groups according to whether the HAI change on the points increased or decreased. The scattered point diagrams of the two sample point groups were also produced (Fig. 4d,e).
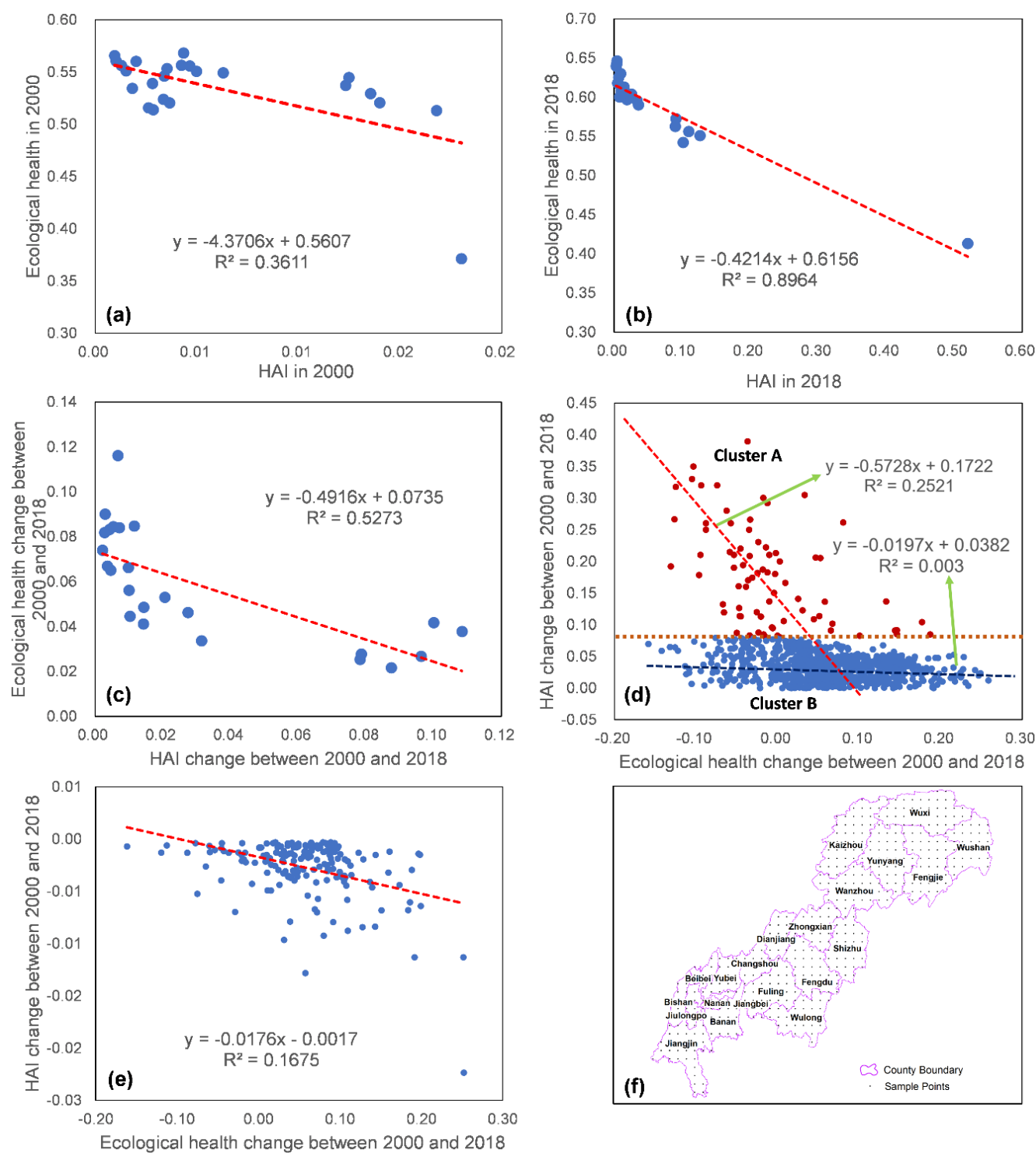

Figure 4. Relationship between ecological health and human activity intensity on a county scale (a) in 2000, (b) in 2018, and (c) between 2000 and 2018; scattered sample points experiencing $H A I(\boldsymbol{d})$ increase and $(\boldsymbol{e})$ decrease; $(\boldsymbol{f})$ county and sample point distribution 
According to Figure $4 a, b$, there was a significant negative relationship between HAI and ecological health in both 2000 and 2018. Comparatively, the coefficient of determination $\left(\mathrm{R}^{2}\right)$ that we yielded in $2018\left(\mathrm{R}^{2}=0.89\right)$ was larger than that in 2000 $\left(\mathrm{R}^{2}=0.36\right)$. Therefore, in the Three Gorges Reservoir Region from 2000 to 2018, the impact of human activity pressure on the ecosystem became more serious. It could be further confirmed by the significant negative correlation between HAI and ecological health changes, exhibited in Figure $4 c$. On the finer scale, by classifying the sample points according to increase or decrease of HAI, we safely obtained two laws: in areas where HAI had increased, ecological health was prone to worsening (Fig. 4d); in areas where HAI had decreased, ecological health improved (Fig. 4e). Notably, if we check the Figure $4 d$ carefully, the sample points could be divided into two clusters: cluster A composed of sample points with HAI increase exceeding 0.08 , and cluster B composed of the others with relative less HAI increase. The linear regression analysis shows that, only when the increase of HAI is beyond 0.08 , its impact on ecological health toward deterioration is significant (e.g., cluster A). When it is below 0.08 , there is no remarkable effect (e.g., cluster B). In contrast, in the Figure $4 e$, with the decrease of HAI, the ecological health improved constantly and significantly. Therefore, in different ranges of HAI change, its effects on ecological health could vary greatly.

To sum up, it is explicit that the spatial reorganization of HAI has significantly driven the evolution of ecological health from 2000 to 2018 in the Three Gorges Reservoir Region. Nevertheless, Figure 4 only revealed the general relationship between HAI and ecological health for the entire study area.

The advantages of the grid-scale spatial data enabled us to put insights into each county of study area. By using the GIS technology, we generated 100 uniformly distributed sample points in each county. The grid-values of ecological health and HAI were extracted to the sample points, and then ecological health change from 2000 to 2018, and the correlation coefficients between ecological heath and HAI for each county were calculated. From Figure 5, we found an especial phenomenon: there were a group of counties (Yuzhong, Yubei, Shapingba, Nanan, Jiulongpo, Jiangbei, Dadukou, Beibei and Banan), with relative lower ecological health improvement and irregular fluctuation of correlation coefficients, did not follow the rule illuminated in the Figure 4. The rest counties belong to the other group with higher ecological health increase and keep consistent with the rule exhibited for the entire study area. Interestingly, all the counties of first group were collectively located in urban areas with high economy development (developed counties), which accounted for merely $11.25 \%$ of the total area of TGRR; the counties in the second group all had backward economic development (developing counties), and mainly distributed in remote mountainous areas. This found might optimize the finding obtained from Figure 4. The impacts of human activity intensity on the evolution of ecological health would be more significant in remote mountainous areas than urban areas. Thus, we believe that, making a difference between remote mountains areas and urban areas, should be essential for better understanding the driving mechanism of human activity on ecological health change in the future study in TGRR.

\section{A Special Case in TGRR}

When compared to other places reported by previous studies of ecosystem evolution, what happened in TGRR is unique. Many studies reported on ecosystem degradation in ecologically fragile regions, especially in remote mountainous areas with serious 
conflict between increasing human populations and limited natural resources (Han et al., 2020), such as the northeast Tibetan Plateau (Liu et al., 2020), the Eastern Black Sea Region (Bekci, 2021), and the Manica Highlands of southern Africa (Clark et al., 2019). In these places, increasing population pressure and food shortages have forced residents to exploit remaining natural resources with unsustainable activities such as deforestation, overgrazing, and the reclamation of cultivated land, thereby exacerbating ecosystem degradation. Ecosystem degradation conversely worsens food production, and then leads to more exploitation. This is called a vicious cycle of ecosystem degradation.

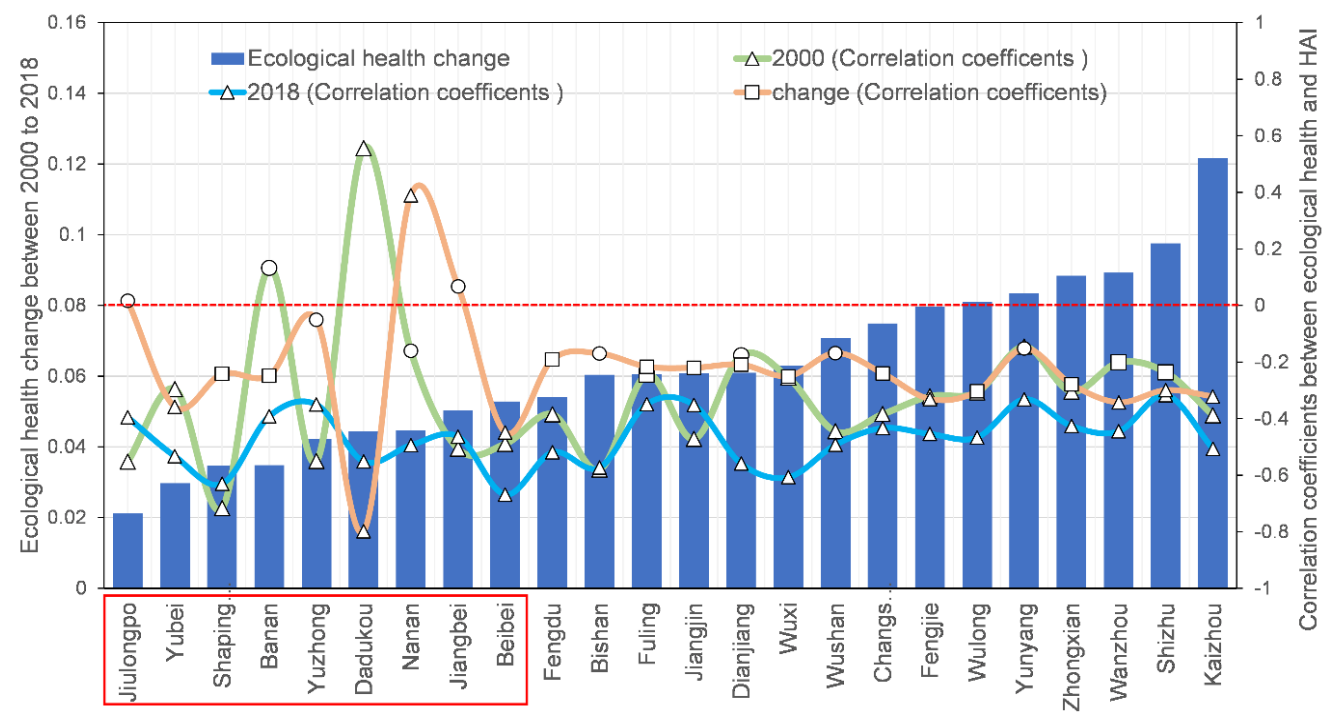

Figure 5. Ecological health change from 2000 to 2018, and the correlation coefficients between ecological heath and HAI for each county ( $\triangle$ : highly significant correlation $(P<0.01)$, $\square$ : significant correlation $(P<0.05)$, $\circ$ : no significant correlation)

The Three Gorges Reservoir Region is a typical ecologically fragile region with serious conflict between increasing human populations and limited land surface (Tong et al., 2018). However, according to our study, it jumped out of the vicious cycle of ecosystem degradation, and achieved an obvious improvement of ecological health from 2000 to 2018. Although ecological health was negatively correlated with HAI, the ecological environment of remote mountainous areas widely distributed in the study area had the opportunity to recover because of the spatial reorganization of human activity intensity. Large-scale and long-term population migrants in the Three Gorges Reservoir Region have deeply influenced the spatial reorganization of human activity intensity (Li and Tan, 2018), which might lastly foster the uniqueness of ecological health evolution. At present, study of the relationship between human activity and ecological health continues to deepen (Jaiswal and Pandey, 2021). In the Chuandong region of China, Han et al. (2020) found that the negatively linear relationship between human disturbances and ecosystem service varied across different terrain gradients. In the Three Gorges Reservoir Region, we identified that variation between remote mountains areas and urban areas, which has not been reported by previous studies. It might be another unique characteristic of the study area. Our study quantitatively clarified the relationship between HAI and ecological health on a finer scale, which 
enable us to yield detailed effecting natures of human pressure on ecological health. Using measured migrant population data with questionnaire surveys to explore the internal impact mechanisms of human activity on ecosystem changes will be a research trend in the Three Gorges Reservoir Region.

\section{Conclusion}

We established a three-level index system for ecological health assessment in the Three Gorges Reservoir Region by using the PSR model, and calculated the ecological health products of 2000 and 2018, respectively. We found an overall improvement in ecological health from 2000 to 2018. With regard to the standardized indices, except for the population density index, which slightly decreased, the five other standardized indices (resilience, vegetation, organization, ecosystem service, and fragmentation indices) were all increased to some extent. Around the metropolitan area, a deterioration circle of the ecological system exists. From 2000 to 2018, there was significant spatial reorganization of human activity intensity triggered by the migrant population from mountainous areas to cities. Ecological health was negatively correlated to HAI both in 2000 and 2018. From 2000 to 2018, the impact of HAI on ecological health has significant spatial heterogeneity. In areas where HAI had increased, ecological health was prone to becoming worse, and only when the increase of HAI is beyond 0.08 , its impact on ecological health toward deterioration is significant; in areas where HAI had decreased, ecological health improved constantly and significantly according to statistical analysis. Compared to urban areas, the effect of HAI change on ecological health is more outstanding in remote mountain areas, where the reduction of HAI promoted the restoration of the ecosystem.

Our study first applied human activity intensity (HAI) to quantitatively represent human pressure on the ecosystem, and attempted to clarify the relationship between HAI and ecological health on a finer scale to overcome the shortcomings of the county scale in the Three Gorges Reservoir Region. Nevertheless, the impact mechanism of specific human activity (e.g., reclaiming farmlands, afforestation, rural laborers moving out to work) on ecological health is still obscure. In the future, employing detailed household survey data that are specifically tailored to the migrant population-human activity-ecosystem relationship would promote a deeper understanding of the related mechanisms.

Acknowledgments. This work was supported by Chongqing Research Program of Basic Research and Frontier Technology (No. cstc2019jcyj-msxmX0515), National Natural Science Foundation of China (No. 42001388, 41771460, 41801063), Project funded by China Postdoctoral Science Foundation (No. 2019M653830XB), Youth Innovation Promotion Association, China (No. 2018417).

Conflicts of Interests. The authors declare no conflict of interests.

\section{REFERENCES}

[1] Allen, C. D., Savage, M., Falk, D. A., Suckling, K. F., Swetnam, T. W., Schulke, T., Stacey, P. B., Morgan, P., Hoffman, M., Klingel, J. T. (2002): Ecological restoration of southwestern ponderosa pine ecosystems: a broad perspective. - Ecological Applications 12: $1418-1433$. 
[2] Bebianno, M. J., Pereira, C. G., Rey, F., Cravo, A., Duarte, D., D'Errico, G., Regoli, F. (2015): Integrated approach to assess ecosystem health in harbor areas. - Science of the Total Environment 514: 92-107.

[3] Bekci, B. (2021): A case study on the interdependence between the coastal ecosystem and humankind. - Ocean \& Coastal Management 210: 105666.

[4] Cao, S. X., Ma, H., Yuan, W. P., Wang, X. (2014): Interaction of ecological and social factors affects vegetation recovery in China. - Biological Conservation 180: 270-277.

[5] Chen, P. (2007): Ecological health assessment at the landscape scale based on RS and GIS, A case study from the New District of a Bay-type city. - Acta Scientiae Circumstantiae 27(10): 1744-1752.

[6] Chen, C. D., Cheng, H., Jia, J. S., Wang, X. Y., Zhao, J. J. (2019): Use it or not: An agroecological perspective to flooded riparian land along the Three Gorges Reservoir. Science of the Total Environment 650: 1062-1072.

[7] Clark, V. R., Vidal, J. D., Grundy, I. M., Fakarayi, T., Childes, S. L., Barker, N. P., Linder, H. P. (2019): Bridging the divide between intuitive social-ecological value and sustainability in the Manica Highlands of southern Africa (Zimbabwe-Mozambique). Ecosystem Services 39: 100999.

[8] Costanza, R., Norton, B. G., Haskell, B. D. (1992): Ecosystem Health: New Goals for Environmental Management. - Island Press, Washington, DC.

[9] Ding, X. K., Wang, Y. Q., Han, Y. G., Fu, J. (2020): Evaluating of net anthropogenic nitrogen inputs and its influencing factors in the Three Gorges Reservoir Area. - China Environmental Science 1: 206-216.

[10] D’Odorico, P., Bhattachan, A., Davis, K. F., Ravi, S., Runyan, C. W. (2013): Global desertification: drivers and feedbacks. - Advances in Water Resources 51: 326-344.

[11] Du, P. J., Xia, J. S., Du, Q., Luo, Y., Tan, K. (2013): Evaluation of the spatio-temporal pattern of urban ecological security using remote sensing and GIS. - International Journal of Remote Sensing 34: 848-863.

[12] Feng, Q., Ma, H., Jiang, X. M., Wang, X., Cao, S. X. (2015): What has caused desertification in China? - Scientific Reports 5: 15998.

[13] Halpern, B. S., Walbridge, S., Selkoe, K. A., Kappel, C. V., Micheli, F., D'Agrosa, C., Bruno, J. F., Casey, K. S., Ebert, C., Fox, H. E., Fujita, R., Heinemann, D., Lenihan, H. S., Madin, E. M., Perry, M. T., Selig, E. R., Spalding, M., Steneck, R., Watson, R. (2008): A global map of human impact on marine ecosystems. - Science 319: 948-952.

[14] Han, R., Feng, C.-C., Xu, N., Guo, L. (2020): Spatial heterogeneous relationship between ecosystem services and human disturbances: A case study in Chuandong, China. Science of The Total Environment 721: 137818.

[15] He, J. H., Pan, Z. Z., Liu, D. F., Guo, X. N. (2019): Exploring the regional differences of ecosystem health and its driving factors in China. - Science of the total environment 673: 553-564.

[16] Jaiswal, D., Pandey, J. (2021): Human-driven changes in sediment-water interactions may increase the degradation of ecosystem functioning in the Ganga River. - Journal of Hydrology 598: 126261.

[17] Jin, Y., Yang, W., Sun, T., Yang, Z., Li, M. (2016): Effects of seashore reclamation activities on the health of wetland ecosystems: a case study in the Yellow River Delta, China. - Ocean \& Coastal Management 123: 44-52.

[18] Li, Y., Li, D. (2014): Assessment and forecast of Beijing and Shanghai's urban ecosystem health. - Science of the Total Environment 487: 154-163.

[19] Li, B., Li, X., Bouma, T. J., Soissons, L. M., Cozzoli, F., Wang, Q., Zhou, Z., Chen, L. (2017): Analysis of macrobenthic assemblages and ecological health of Yellow River Delta, China, using AMBI \& M-AMBI assessment method. - Marine Pollution Bulletin 119(2): 23-32. 
[20] Li, W., Tan, H. M. (2018): Spatial redistribution of populations in mountainous areas and its impact on vegetation change in southwest China: A riverside case study. - Acta Ecologica Sinica 38(24): 8879-8887.

[21] Li, S. C., Zhang, Y. L., Wang, Z., Li, L. (2018): Mapping human influence intensity in the Tibetan Plateau for conservation of ecological service functions. - Ecosystem Services 30: 276-286.

[22] Liao, C. J., Yue, Y. M., Wang, K. L., Fensholt, R., Tong, X. W., Brandt, M. (2018): Ecological restoration enhances ecosystem health in the karst regions of southwest China. - Ecological Indicators 90: 416-425.

[23] Liu, R., Xiao, L. L., Liu, Z., Dai, J. C. (2018): Quantifying the relative impacts of climate and human activities on vegetation changes at the regional scale. - Ecological Indicators 93: 91-99.

[24] Liu, C. L., Li, W. L., Zhu, G. F., Zhou, H. K., Yan, H. P., Xue, P. F. (2020): Land use/land cover changes and their driving factors in the Northeastern Tibetan Plateau based on geographical detectors and google earth engine: a case study in Gannan Prefecture. - Remote Sensing 12(19): 3139.

[25] Liu, Y. Q., Lv, C. H., Fu, B. J. (2021): Terrestrial ecosystem classification and its spatiotemporal changes in China during last 20 years. - Acta Ecologica Sinica 41(10): 3975-3987.

[26] Ma, D., Liu, Z. Y., Liu, S. H., Notaro, M., Rong, X. Y., Chen, G. S., Wang, F. Y. (2013): Short term effects of vegetation changes in the East Asian monsoon on local climate. Science Bulletin 58(17): 1661-1669. (in Chinese).

[27] Ma, H., Wang, Y. Q., Wang, L., Wang, Y. K. (2014): Coupling relationship between vegetation cover and climate change and rural economic development in rocky desertification area in recent 20 years in China. - Journal of Mountain Science 32(1): 3845. (in Chinese).

[28] Myneni, R., Asrar, G., Hall, F. (1992): A three-dimensional radiative transfer method for optical remote sensing of vegetated land surfaces. - Remote Sensing of Environment 41: 105-121.

[29] Neri, A. C., Dupin, P., Sánchez, L. E. (2016): A pressure-state-response approach to cumulative impact assessment. - Journal of Cleaner Production 126: 288-298.

[30] Nilsson, C., Reidy, C. A., Dynesius, M., Revenga, C. (2005): Fragmentation and flow regulation of the world's large river systems. - Science 308(5720): 405-408.

[31] Niu, M. X., Wang, J., Xu, B. D. (2017): Assessment of the ecosystem health of the YellowRiver Estuary based on the pressure-state-response model. - Acta Ecologica Sinica 37: 943-952. (in Chinese).

[32] Saaty, T. L., Vargas, L. G. (2001): Models, Methods, Concepts \& Applications of the Analytic Hierarchy Process. - Springer, Boston, MA.

[33] Sanderson, E. W., Jaiteh, M., Levy, M. A., Redford, K. H., Wannebo, A. V., Woolmer, G. (2002): The human footprint and the last of the wild. - Bioscience 52: 891-904.

[34] Schumacher, P., Mislimshoeva, B., Brenning, A., Zandler, H., Brandt, M., Samimi, C., Koellner, T. (2016): Do red edge and texture attributes from high-resolution satellite data improve wood volume estimation in a semi-arid mountainous region? - Remote Sensing 8: 540.

[35] Shao, J. A., Dang, Y. F., Wang, W., Zhang, S. C. (2018): Simulation of future land-use scenarios in the Three Gorges Reservoir Region under the effects of multiple factors. Journal of Geographical Sciences 28(12): 1907-1932.

[36] Shi, Z. G., Yan, X. D., Yin, C. H., Wang, Z. M. (2007): Impact of historical changes in human land use on climate. - Chinese Science Bulletin 52(12): 1436-1444. (in Chinese).

[37] Sivakumar, M. V. K. (2007): Interactions between climate and desertification. Agricultural and Forest Meteorology 142: 143-155. 
[38] Sun, X. P., Wang, T. M., Ko, X. J., Ge, J. P. (2012): Analysis of long-time sequential normalized vegetation index changes and their driving forces in the Jinghe river basin of the loess plateau. - Chinese Journal of Plant Ecology 36(6): 511-521. (in Chinese).

[39] Tang, D., Zou, X., Liu, X., Liu, P., Zhamangulova, N., Xu, X., Zhao, Y. (2015): Integrated ecosystem health assessment based on eco-exergy theory: a case study of the Jiangsu coastal area. - Ecological Indicators 48: 107-119.

[40] Tong, L., Liu, C., Nie, H. (2016): Assessing future vegetation trends and restoration prospects in the karst regions of southwest China. - Remote Sensing 8: 357.

[41] Tong, X., Brandt, M., Yue, Y., Horion, S., Wang, K., De Keersmaecker, W., Tian, F., Schurgers, G., Xiao, X., Luo, Y. (2018): Increased vegetation growth and carbon stock in China karst via ecological engineering. - Nature Sustainability 1: 44.

[42] Walz, R. (2000): Development of environmental indicator systems: experiences from Germany. - Environmental Management 25: 613-623.

[43] Wang, Y. H., Geng, Y. H. (2013): Effects of soil water losses during different ecological restoration stages of small watersheds in the Three Gorges Reservoir Area. - Journal of Soil and Water Conservation 27(4): 78-82.

[44] Wu, J. G. (2000): Landscape Ecology: Pattern, Process, Scale and Hierarchy. - Higher Education Press, Beijing.

[45] Wu, L., You, W., Ji, Z., Xiao, S., He, D. (2018): Ecosystem health assessment of Dongshan Island based on its ability to provide ecological services that regulate heavy rainfall. - Ecological Indicators 84: 393-403.

[46] Xie, G. D., Lu, C. X., Leng, Y. F., Zheng, D., Li, S. C. (2003): Ecological assets valuation of the Tibetan Plateau. - Natural Resources Journal 18: 189-196.

[47] Zhang, L. L., Liu, J. L., Yang, Z. F., Li, Y., Yang, Y. (2013): Integrated ecosystem health assessment of a macrophyte-dominated lake. - Ecological Modelling 252(1): 141-152.

[48] Zhang, B. L., Gao, J. B., Gao, Y., Cai, W. M., Zhang, F. R. (2018): Land use transition of mountainous rural areas in China. - Acta Geographica Sinica 73(3): 503-517. (in Chinese).

[49] Zhao, H. B., Zheng, H., Miao, C. H. (2016): Spatial-temporal pattern and factor diagnoses of agroecosystem health in major grain producing areas of Northeast China: A case study in Jilin Province. - Chinese Journal of Applied Ecology 27(10): 3290-3298. (in Chinese). 